\title{
Seismic vulnerability assessment of health facilities in Mexico City, Mexico
}

\author{
S. Morán-Rodríguez ${ }^{1} \&$ D. A. Novelo-Casanova ${ }^{2}$ \\ ${ }^{1}$ Ciencias de la Tierra, Instituto de Geofísica, \\ Universidad Nacional Autónoma de México, Mexico \\ ${ }^{2}$ Departamento de Sismología, Instituto de Geofisica, \\ Universidad Nacional Autónoma de México, Mexico
}

\begin{abstract}
We developed a model to estimate the seismic vulnerability of health facilities consisting of three phases: 1) Design of a Normative Theoretical Framework (NTF) considering structural, non-structural, functional, and social-administrative elements; 2) Identification of the vulnerability conditions of the analyzed structure by using the NTF; 3) Estimation of the level of vulnerability to seismic hazards of the health facility by comparing the measured vulnerability of the installation with the optimal theoretical indicators. This methodology was applied to three hospitals in Mexico City: Cardiology Hospital of the National Medical Center "Siglo XXI" $(\mathrm{CaH})$, the Children's Hospital "Dr. Federico Gómez" $(\mathrm{ChH})$ and the "Hospital de Jesus" (JeH). Our results indicate that the JeH is the most vulnerable of the three cases of study with very high levels of vulnerability in the non-structural, socialadministrative and structural elements. In the $\mathrm{ChH}$, the social-administrative element was classified with moderate levels of vulnerability. In the non-structural as well as in the functional elements, this hospital has high levels of vulnerability. In the structural element only two buildings of its installations have very high levels of vulnerability. The $\mathrm{CaH}$ was identified with low and moderate, high, and very high in the structural, functional and socio-administrative, and non-structural elements, respectively. In general, the very high and high levels of vulnerability measured in the three hospitals: 1) In the social-administrative and functional element can be significantly reduced with the establishment of an operational emergency plan; 2) In the non-structural element is mainly due to problems related to roofs' overweight, connecting bridges among the different installations and the lack of regular maintenance; 3 ) In the structural element is due to the architectural
\end{abstract}


shape of the buildings, type of construction, lack of maintenance and the poor technology to stand seismic shaking.

Keywords: vulnerability of health facilities, vulnerability, Mexico City, seismic hazard.

\section{Introduction}

Although health facilities are essential infrastructure during disasters and emergencies in any urban area, they also are usually highly vulnerable installations in the case of the occurrence of a local large earthquake. Thus, it is important to maintain the operability of a hospital after the impact of an earthquake to satisfy the need for medical care of the affected population [1].

Damage in hospitals can cause devastating secondary disasters. In December 2004, the Indian Ocean tsunami disaster affected the entire national healthcare system and millions of beneficiaries of the Aceh province. It damaged $61 \%$ of health facilities and killed approximately $7 \%$ of its health workers [2]. As a consequence, Aceh's public health system recovery required intensive investment. For these reasons, it is important to carefully design the structure as well as the geological and geographical location of hospitals to minimize their exposure to seismic hazards [3, 4]. Also, it is necessary to implement non-structural mitigation measures and legalize building regulations of countries located in areas highly exposed to seismic hazards $[5,6]$.

The most recent devastating earthquake in Mexico City occurred on 19 September 1985 (magnitude 8.1) [7]. During this earthquake, five main health facilities suffered major damage. At least 11 hospitals had to be evacuated and in total, 856 people lost their lives in two collapsed hospitals [8,9]. Also, 13 hospitals of six or more floors were partially or totally destroyed. One out of every four hospitals' beds in the city was lost. More than 900 patients, physicians, nurses and paramedical workers died in the initial shock [10]. Morán-Rodríguez and NoveloCasanova [11] determined that about $70 \%$ of the most important health's infrastructure in Mexico City has a level of exposure to seismic hazards between moderate and high. The other 30\% although has a low level of exposure, the level of damage during a large earthquake will depend on their vulnerability conditions. These authors identified that more than $50 \%$ of the main and reference hospitals in Mexico City are highly exposed to seismic hazards.

At present, there are different methodologies to estimate seismic hazards. Cardona and Hurtado [12] developed a holistic approach to estimate seismic risk incorporating geological and structural elements as well as social, political, and cultural aspects, even the responsiveness and recovery system after the occurrence of an earthquake. The method uses mathematical tools to estimate the seismic hazard in cities or urban areas determining a Risk Management Indicator (RMI). This methodology allows measuring key factors of countries' vulnerability to natural hazards and the level of performance of the local disaster risk management [13].

The Community Vulnerability Assessment Tool (CVAT) is a risk and vulnerability assessment methodology designed by the National Oceanic and 
Atmospheric Administration's Coastal Services Center (NOAA) to assist emergency managers and planners in their efforts to reduce vulnerability through hazard mitigation, comprehensive land use, and development planning [14].

All methodologies described above measure the risk to natural hazards in a city and the critical facilities are taken as an integral part of a measured indicator. As a result, the vulnerability and risk analysis of a determined health facility is not complete. Specific methods for assessing the risk of health facilities are few, among these we find the Vulnerability Assessment of Health Care Facilities during Disaster Events (VAHCF) that measures the operational vulnerability of a health care facility during disaster events [15]. The guidelines of the Safe Hospital Program (SHP) developed by the Mexican Government (SEGOB) and the Mexican National System for Civil Protection (SINAPROC) define a "safe hospital" as a unity whose services remain accessible and functional at maximum capacity and within the same infrastructure immediately following a disaster [16]. The VAHCF and SEGOB methods consider the administration and organization conditions in health facilities to obtain a risk indicator. However, no one of these methodologies provides a level of vulnerability.

Vulnerability indexes in a determined model must consider the relative importance of each element involved as well as the interaction among these elements. Thus, a model system is a set of interrelated elements with a cohesion and purpose. The behavior of a system is understood as the dependence to the answers of the stimulus received [17]. An example is the fact that the response of a non-structural element in case of disasters depends on the safety of the structural element and the safety of a structural element depends on proper maintenance and use of seismic technology in its components. These concepts when are applied to the measurement of vulnerability to seismic hazards make a convenient approach because it can extend the framework of the evaluation by including the different elements involved in the operation and safety of the facility and in the emergency response.

The methodology developed here represents a holistic approach to determine the seismic vulnerability in a hospital and uses numerical values weighted according to the importance of the elements considered. The estimated seismic vulnerability is the result of the combination of the structural, non-structural, functional, and social-administrative characteristics of the analyzed hospital.

\section{Method}

Our model was developed based on a system of indicators estimated using a Normative Theoretical Framework (NTF). This NTF considers the occurrence of an earthquake of magnitude 8 or greater impacting Mexico City and is based on existing international standards and recommendations for risk management in hospitals $[4,6,14,16]$. The model takes into account the following elements:

1. Structural: identifies those structural problems that will cause damage to the structural components of the installations (load-bearing walls, concrete slabs, architectural shapes, construction joints, overweight to the original construction, etc.). 
2. Non-structural: those components that are not part of the resistant system of the structure and that are crucial to the effective operation of the facility (medical equipment, doors, windows, walls, electricity, air conditioning, gas, emergency system or equipment, furniture, etc.).

3. Functional: includes the geographical location of the hospital's buildings as well as the use of the architectural spaces, conditions of local hygiene and security, and the analyses of outdoor areas.

4. Social-administrative: analyzes the administration and organization in the health facility to mitigate the impact of a disaster and the existing emergency and evacuation plans.

As part of our methodology, we consider the following definitions:

- Parameter: components of any of the four elements (walls, roofs, furniture, equipment, etc.);

- Unit: problem detected for each parameter (broken windows, unlocked baby cribs, lack or inadequate response plans, lack of regular building maintenance, etc.).

We considered 10 parameters for each element and 65 units for each parameter with a previously assigned numerical value [18].

\section{Step 1: Design of the NTF}

\section{Step 1.1: Determination of theoretical indicators}

Four theoretical Indicators $(T I)$ are obtained according to the following equations:

$$
\begin{aligned}
& T I A=V A * w_{a} \\
& T I B=V B * w_{b} \\
& T I C=V C * w_{c} \\
& T I D=V D * w_{d}
\end{aligned}
$$

where $T I A, T I B, T I C$ and $T I D$ are the structural, non-structural, functional, and social-administrative theoretical indicator elements, respectively. $V A, V B, V C$, and $V D$ represent the vulnerability of each element obtained from the sum of the unit's numerical values. $w$ is the weight assigned to the corresponding TI according to its importance with respect to the other elements as explained below.

In this work, $T I D$ is considered as the most important element for reducing vulnerability in a hospital. For this reason, we assigned a weight of 1.00 . This is justified by the fact that actions for mitigating risk and reducing vulnerability depends on the decisions of the authorities and personnel of the hospital [4]. TIA is weighted with 0.80 . This weighting scheme is based on the assumption that from the structural stability depends the security of the building [16, 19]. The nonstructural parameter was weighted with 0.60 . This parameter is considered the third most important in our model because damage in the non-structural parameter supposes substantial economic losses in any hospital [20]. The functional element was weighted with 0.40 because this element has the less influence in the installation's security [16] (table 1).

We used the following classification of damage [18]: DL = damage to life; DF $=$ damage that limits the operability of the hospital; $\mathrm{DO}=$ damage that inhibits the optimal operation. The greatest damage is DL to which we assigned a weight equal to 1 . To DF we considered a weight of 0.80 because it generates less damage with 
respect to DL. To DO we assigned a weight of 0.40 because it is less important than the previous two kinds of damages. We assigned lower weights to the nonstructural and functional parameters because from the structural system and socialadministrative elements depends the safety and performance of the health facility $[3,6,16,19]$.

Table 1: Values of theoretical indicators.

\begin{tabular}{|c|c|c|c|}
\hline $\begin{array}{c}\text { Vulnerability } \\
\text { (element) }\end{array}$ & $\begin{array}{c}\text { Numerical value } \\
\text { (sum of unit's values) }\end{array}$ & $\begin{array}{c}\text { Weight } \\
(w)\end{array}$ & $\begin{array}{c}\text { Theoretical Indicator } \\
\text { (see eqns (1) to(4)) }\end{array}$ \\
\hline VD & 51.40 & 1.00 & 51.40 \\
\hline VA & 50.04 & 0.80 & 40.03 \\
\hline VB & 50.26 & 0.60 & 30.16 \\
\hline VC & 26.56 & 0.40 & 10.62 \\
\hline
\end{tabular}

\section{Step 1.2: Weighting}

Three weighting factors are considered [18]:

1. Classification of Areas (CA). Area A: Zone of vital importance to protect life. One hundred percent of these areas are required to operate during the emergency in the hospital. Thus, we arbitrarily multiply by 2.0 the numerical vulnerability measured for these areas; Area B: these areas are less important for the operation of the hospital. However, we consider that at least $80 \%$ of these facilities must operate during an emergency by multiplying the obtained numerical vulnerability by 1.8 ; Area $\mathrm{C}$ : these areas are less important than Areas $\mathrm{B}$ and it is considered that at least $20 \%$ of these facilities must be functional in disaster situations. Thus, we multiply the measured numerical vulnerability for these areas by 1.2. This classification of areas is not applied to the structural element.

2. Topology of Construction (TC). TC is determined by classifying the characteristics of the building material of the hospital. This classification varies from the most vulnerable installations to the response to seismic waves of those facilities that have incorporated anti-seismic technology. We consider six categories classified from $\mathrm{A}$ to $\mathrm{F}$ with $\mathrm{A}$ as the most vulnerable installation and $\mathrm{F}$ the less vulnerable. To category A we assign a value of 1 . From this value, the others categories decrease by 0.20 from one category to another one.

3. Seismic Hazard (SH). The Mexico City's building code [22] classifies the soil of the city in three seismic zones: Zone I (hill zone) is mainly basalt lava flows with little water content; Zone II (transition zone) is composed of sands with fairly high water content from eroding volcanic cones that surround the Valley of Mexico; Zone III (lakebed zone) consists of silt and volcanic clay sediments of the bed of the historic Lake Texcoco with high water content and exhibits a huge amplification of ground motion resulting in severe damage to the installations located in this area. For this reason, we granted to Zone III a weight of 1. Because in Zone II the expected damage is less than in Zone III, we considered a value of 0.60 and to Zone I we assigned 0.20 because this is the area with less probability of damage. 


\section{Step 2: Data collection based on the NTF}

\section{Step 2.1: Data collection}

Using the NTF as reference, all problems that increase or decrease the vulnerability of the the health facility are identified, quantified and classified according to the numerical value of each unit of analysis previously established [18]. This value depends on the level of damage that the identified problem can cause to DL, DF or DO. Once the value of each unit is determined, all them are added to obtain the corresponding $V A, V B, V C$ and $V D$ (eqns 1 to 4 ).

\section{Step 2.2: Weighting of the vulnerability index (VI) measured}

The numerical values of the $V I$ are determined as follows:

$$
\begin{aligned}
& V I A= {[V A *(T C+S A)]^{*} w_{a} } \\
& V I B=V B^{*} w_{b} \\
& V I C=V C^{*} w_{c} \\
& V I D=V D^{*} w_{d}
\end{aligned}
$$

where $V I A, V I B, V I C$ and $V I D$ are the structural, non-structural, functional and social-administrative vulnerability indexes, respectively. $w$ is the weight assigned to the corresponding $V I$ according to its importance with respect to others elements (table 1).

\section{Step 3: Estimation of the level of vulnerability}

As final step, the measured values of $V I A, V I B, V I C$, and $V I D$ are normalized with respect to corresponding indicators of the NTF. Then, the level of vulnerability is determined according to table 2 .

Table 2: Levels of vulnerability.

\begin{tabular}{|c|c|l|}
\hline $\begin{array}{c}\text { Descriptive level } \\
\text { of vulnerability }\end{array}$ & $\begin{array}{c}\text { Level of } \\
\text { vulnerability }\end{array}$ & \multicolumn{1}{c|}{$\begin{array}{c}\text { Observations and recommended } \\
\text { mitigation measures }\end{array}$} \\
\hline Unacceptable & $0.81-1.0$ & $\begin{array}{l}\text { Re-structuring of buildings to warrant safety and } \\
\text { functionality is completely necessary. Most } \\
\text { elements of the hospital are in very high risk and } \\
\text { structural collapse is possible. }\end{array}$ \\
\hline Very high & $0.61-0.8$ & $\begin{array}{l}\text { The implementation of mitigation measures to } \\
\text { diminish the level of vulnerability is necessary. } \\
\text { The health facility is in very high risk of losing } \\
\text { functionality and safety. }\end{array}$ \\
\hline High & $0.41-0.6$ & $\begin{array}{l}\text { The implementation of actions to reduce the } \\
\text { vulnerability to an acceptable level is urgent to } \\
\text { warrant safety and performance of the institution. } \\
\text { The hospital is in high risk to suffer severe } \\
\text { damage. }\end{array}$ \\
\hline Moderate & $0.21-0.4$ & $\begin{array}{l}\text { The hospital can suffer some damage affecting the } \\
\text { functionality of the installation. }\end{array}$ \\
\hline Low & $0.00-0.2$ & $\begin{array}{l}\text { Regular building maintenance and updating the } \\
\text { response and mitigation plans is recommended. }\end{array}$ \\
\hline
\end{tabular}


A schematic summary of the procedures to follow after the NTF has been established is shown in fig. 1 .

To assess the vulnerability we use different tools [18]: Tool 1. Guidelines to classify hospital's areas. This allows to classify the different types of areas in the health facility; Tool 2. Form for structural assessment. With this tool the current condition of the structure system is identified as well as the age of construction, type of building system, architectural configuration problems, and past damages in the structural and non-structural architectural elements; Tool 3. Form to assess the interior areas. This allows to identify the probable damages in each area of the hospital by classifying the problems according to the TIA, TIB, TIC and TID parameters (eqns (1) to (4)); Tool 4. Form to assess the outdoor areas. This tool detects those outdoor problems that increase vulnerability; Tool 5. Table of Units. This table classifies the problems identified that increase or decrease vulnerability and generates a complete report of potential and existing damages; Tool 6 . Graphical representation of identified problems and possible damages. It displays the causes of the level of vulnerability and possible solutions to reduce this vulnerability as well as a summary of probable damages. It identifies the problems that must be attended immediately and prioritize mitigation actions.
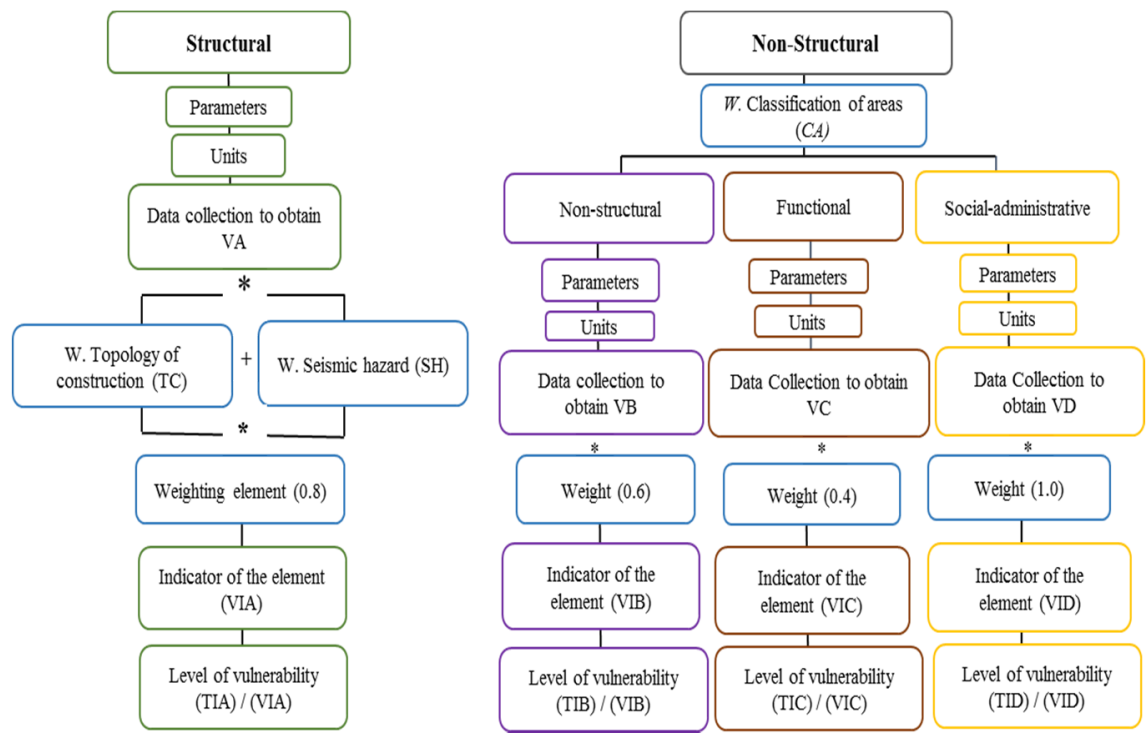

Figure 1: Schematic procedure to estimate the level of vulnerability.

\section{Results and discussion}

Using the methodology described above, we determined that the Mexico Children's Hospital $(\mathrm{ChH})$ has a high level of structural vulnerability, particularly the "Mundet" building and the laundry and machinery installations, table 3; fig. 2(a). Thus, these buildings have very high probability to be seriously damaged 
in case of the occurrence of a major earthquake in Mexico City. Besides, the architectural shape of the buildings and the geological setting where the hospital's buildings are located increase their risk with passing seismic waves. As a result, we recommend the application of re-structuring measures incorporating earthquake-resistant technology. The non-structural and functional vulnerabilities are high and the social-administrative parameter has a moderate level of vulnerability, fig. 2(b). We believe that if its emergency plan is operational independently of the time of the emergency, this hospital will reduce significantly its vulnerability.

Table 3: Structural vulnerability in the Mexico Children's Hospital.

\begin{tabular}{|c|c|c|c|c|c|}
\hline Building & $\begin{array}{c}\text { Sum of } \\
\text { structural } \\
\text { units (VU) }\end{array}$ & $\begin{array}{l}\text { Construction } \\
\text { material }\end{array}$ & $\begin{array}{l}\text { Weight } \\
(w)^{1}\end{array}$ & $\begin{array}{l}\text { Level of } \\
\text { vulnerability } \\
\left(\mathrm{VU}^{*} w\right)\end{array}$ & $\begin{array}{c}\text { Weighted } \\
\text { vulnerability }^{2}\end{array}$ \\
\hline Mundet & 21.48 & \begin{tabular}{|c|} 
Mixed. armed \\
concrete (HA) with \\
brick walls
\end{tabular} & 1.60 & 34.37 & 27.49 \\
\hline $\begin{array}{l}\text { Federico } \\
\text { Gómez }\end{array}$ & 11.60 & $\begin{array}{c}\text { HA with basic } \\
\text { earthquake-resistant } \\
\text { technology }\end{array}$ & 1.40 & 16.24 & 12.99 \\
\hline $\begin{array}{l}\text { Laundry and } \\
\text { machinery } \\
\text { rooms }\end{array}$ & 19.36 & $\begin{array}{l}\text { Brick with HA } \\
\text { castles and slabs }\end{array}$ & 1.60 & 30.98 & 24.78 \\
\hline $\begin{array}{l}\text { Radiation } \\
\text { therapy } \\
\text { facilities }\end{array}$ & 4.88 & $\begin{array}{l}\text { Mixed. HA with } \\
\text { rubble walls }\end{array}$ & 1.60 & 7.81 & 6.25 \\
\hline Auditorium & 4.88 & \begin{tabular}{|c|} 
HA with basic \\
earthquake-resistant \\
technology
\end{tabular} & 1.40 & 6.83 & 5.47 \\
\hline $\begin{array}{l}\text { Radiotherapy } \\
\text { facilities }\end{array}$ & 2.48 & $\begin{array}{l}\text { Mixed HA with } \\
\text { rubble walls }\end{array}$ & 1.60 & 3.97 & 3.17 \\
\hline $\begin{array}{l}\text { Maintenance } \\
\text { and power } \\
\text { installations }\end{array}$ & 7.08 & $\begin{array}{l}\text { Mixed HA with } \\
\text { rubble walls }\end{array}$ & 1.60 & 11.33 & 9.06 \\
\hline
\end{tabular}

${ }^{1}$ To the weight $w$ was added the value of 1 because all building are located in the seismic Zone III.

${ }^{2}$ Level of Vulnerability * 0.8 (weight assigned to the structural element; see text).

Results for the Cardiology Hospital $(\mathrm{CaH})$ shows that buildings D and $\mathrm{E}$ have moderate vulnerability, fig 2(c). However, in these installations are located areas that provide life support to patients: surgery rooms, intensive care, and laboratories. Because of these reasons, it is necessary to implement actions to reduce vulnerability to a low level to warrant the safety within these buildings. The non-structural parameter has very high level of vulnerability, indicating the need to reduce this vulnerability to an acceptable level by implementing mitigation measures to protect the life of patients and personnel as well as the operability of the building in case of emergencies. The functional and social-administrative parameters were identified with a high level of vulnerability, fig. 2(d). In this case, it is necessary to implement mitigation measures to reduce this type of vulnerability to acceptable levels as well as a proper response plan. 

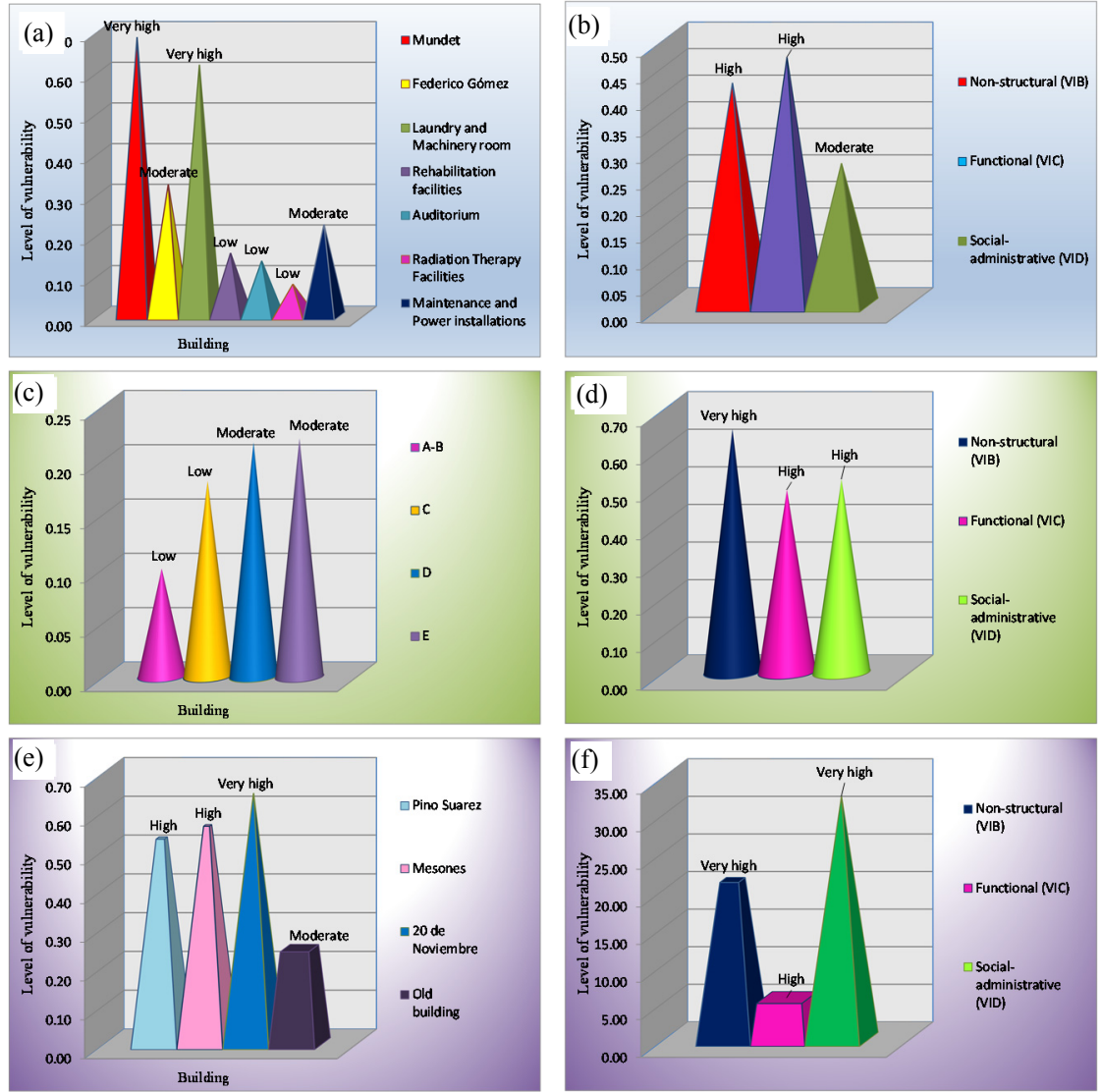

Figure 2: (a)-(b) Structural, non-structural, functional, and socialadministrative vulnerabilities for the Children's Hospital; (c)-(d) same for the Cardiology Hospital; (e)-(f) same for the Jesus Hospital.

For the Hospital de Jesus $(\mathrm{JeH})$ our results show that the higher vulnerability is in the structural element, fig. 2(e). This is mainly due to the structural characteristics of the buildings and their architectural shape. The old building has not serious problems. However, it could suffer considerable damage in case of a major earthquake by the pounding of adjacent buildings. In this case, the losses would be very high, because this building has great historical value being the first health facility established in Latin America in the colonial period. Thus, we consider important to incorporate anti-seismic technology and specific studies of structural engineering to reinforce its structure. It was identified a very high level of non-structural vulnerability mainly because of the lack of safety devices to protect equipment and medical furniture. The socio-administrative element has also very high vulnerability because this hospital has not implemented its emergency plan in case of disasters yet. The functional parameter has a high level 
of vulnerability, fig. 2(f). In general, this installation could suffer serious damage and loss of operability due to the impact of a large earthquake.

Our methodology demonstrates the importance of detailed measurements to determine vulnerability in a health facility to prioritize actions to reduce the impact of a large earthquake. The observed very high and high levels of structural vulnerability in our cases of study are mainly due to the lack of maintenance and technology to stand seismic shaking as well as the use of complex architectural shapes. Other factors that increase the structural vulnerability are the lack of enough separation among the hospital's installations generating the effect of pounding among these buildings in the case of the occurrence of a local earthquake. Also, the type and age of construction as well as heavy objects or architectural elements placed on the roofs of the buildings not considered in the original structural design, increase the susceptibility of these buildings to suffer large damage by passing seismic waves.

Related to the non-structural elements, the main problem are the use of building materials not appropriate for hospitals such as heavy panels in ceilings and large windows with glass surfaces without protection to prevent breaking. The main problems identified in the functional parameter are the lack of brackets on shelves and furniture to avoid downfall objects as well as the need to install locks to beds, baby cribs and other furniture that could fall during a large earthquake. Another factors that increase the functional vulnerability are the lack of installation of flexible material pipes for fluids and building's maintenance. The high level of vulnerability in the social-administrative element is caused by the lack of an emergency plan and of mitigation measures to stand a large earthquake. We believe that it is possible to reduce the risk and vulnerability in hospitals with the application of low cost mitigation measures such as development and implementation of a complete operational emergency plan, providing regular structural maintenance to buildings, removing heavy installation from the roofs of the structures, installing locks in the medical devices and equipment as well as implementing structural studies to incorporate anti-seismic architecture.

\section{Conclusions}

The methodology developed here allows to implement and/or strength existing programs to reduce the levels of structural, non-structural, functional, and socialadministrative vulnerabilities of health facilities in Mexico City. It also identifies those actions needed for proper operation of these installations in disaster situations. The vulnerability problems found in the three cases of study are common among them even having different structural, organization and specialties. For these reasons, we believe that it is important for the Mexican government to develop a special program to determine the level of vulnerability to seismic hazards of at least the main and secondary health facilities in Mexico City by applying this method. Hospitals are only truly safe from disasters when they are functioning at maximum capacity immediately after a hazard strikes.

The JeH is the most vulnerable of the three cases of study with a very high level of vulnerability in the non-structural, social-administrative and structural 
elements. The $\mathrm{ChH}$ has very high level of vulnerability in the structural element. In the operational and the non-structural elements, this hospital has high level of vulnerability. In general, the $\mathrm{CaH}$ was identified with the lowest level of vulnerability in the structural element, however, the operational and the socialadministrative elements were measured with high level of vulnerability. For these three cases of study it is necessary to develop a mitigation plan based on the results of this research. This will allow to significantly reducing their vulnerability in emergency and disaster situations.

\section{Acknowledgements}

The authors are grateful to R. Bonilla-Avila and G. Morán-Rodríguez for their assistance during the field research. Special thanks are due to A. Moran-Balderas and G. Rodriguez-Quiroz for their support during this study. We also appreciate the collaboration of the authorities, medical staff, patients and workers of the Cardiology Hospital, the Children's Hospital and the Hospital de Jesus for their collaboration in obtaining the local data.

\section{References}

[1] Gunn, S.W.A., Health effects of earthquakes, Disaster Prevention and Management, 4(5), pp. 6-10, 1995.

[2] Hospitals Safe from Disasters, Reduce risk, Protect Health Facilities, Save Lives; United Nations, 2008-2009 World Disaster Reduction Campaign Online. www.unisdr.org/wdrc-2008-2009.

[3] Sabido, C.R., Padua, G.A., Rodríguez, M.H., Toledo, B. and Yanez. V.A. (In Spanish), Efectos del terremoto del 19 de septiembre de 1985 en el Hospital. General de la Ciudad de México, Algunas consideraciones. Salud Pública Mexicana, México D.F., (28)5, pp. 521-526, 1986.

[4] Nateghi-Alahi, F. \& Izadkhah, Y.O., Earthquake disaster management. Planning in health care facilities. Disaster Prevention and Management, 13(2), pp. 130-135, 2004.

[5] Fawcett, W. \& Oliveira, C.S., Casualty treatment after earthquake disasters. Development of a regional simulation model, Disasters, 24(3), pp. 271-287, 2000.

[6] Brandeau, M.L., Mccoy, J.H., Hupert, N., Holty, J.E. \& Bravata, D.M., Recommendations for modeling disaster responses in public health and medicine: A position paper of the Society for Medical Decision Making. Journal of Medical Decision Making, 4(29), pp. 438-460, 2009.

[7] UNAM Seismology Group, The September 1985 Michoacan earthquakes: Aftershock distribution and history of rupture. Geophysical Research Letters, (13)6, pp. 573-576, 1986.

[8] Degg, M.D., Earthquake hazard assessment after Mexico (1985). Disasters, 13(3), pp. 237-246, 1989.

[9] Zeballos, J.L., Health aspects of the Mexico earthquake 19th September 1985. Disasters, 10(2), pp. 141-149, 2007. 
[10] Soberon, G.J. and Sepulveda, J., The Health care reform in Mexico: Before and after the 1985 Earthquake. American Journal of Public Health, 76(6), pp. 673-680, 1986.

[11] Morán-Rodríguez S., \& Novelo-Casanova D.A. Spatial Analysis of the Level of Exposure to Seismic Hazards of Health Facilities in Mexico City, Mexico. Geomatics, Natural Hazards and Risk, 3(3), pp. 279-292, 2012.

[12] Cardona, O.D., \& Hurtado, J. E., (In Spanish), Modelación Numérica para la Estimación Holística de Riesgo Sísmico Urbano, Considerando Variables Técnicas, Sociales y Económicas. Documento presentado en. 1er Congreso De Métodos Numéricos en Ciencias Sociales CIMNE-UPC, Barcelona, España, 2000.

[13] Indicadores para la Medición del Riesgo: Fundamentos para un Enfoque Metodológico, (In Spanish). Programa BID/IDEA de Indicadores para la Gestión de Riesgos, Website, Universidad Nacional de Colombia, Manizales, http://idea.unalmzl.edu.co.

[14] Lisa K. Flax, Russell W., Jackson \& David N. Stein, Community Vulnerability Assessment Tool Methodology. Nat. Hazards Rev., 3(4), pp. 163-176, 2002.

[15] Arboleda, C., Abraham, D., Richard, J., and Lubitz, R. Vulnerability Assessment of Health Care Facilities during Disaster Events. Infrastruct. Syst., 15(3), pp. 149-161, 2009.

[16] Secretaria de Gobernación y Sistema Nacional de Protección Civil (In Spanish), Guía Práctica del Programa Hospital Seguro, México Distrito Federal. 24 pp. 2008.

[17] Sandi, H., Vulnerability and risk analysis for individual structures and risk analysis for individual structures and systems. Report of the working group of the European Association for Earthquake Engineering, Lisboa, Portugal, ECEE. 1986.

[18] Morán-Rodríguez, S., (In Spanish), Modelo cuantitativo para la estimación de la Vulnerabilidad de las instalaciones de salud ante un evento sísmico, Tesis doctoral, Universidad Nacional Autónoma de México, México D.F., p. 142, 2012.

[19] Earthquake Engineering Research Institute, National Science Foundation, Reducing Earthquake Hazards: Lessons Learned From Earthquakes, Oakland, California. pp. 10-30, 1996.

[20] Bitrán Bitrán, D., (In Spanish), Impacto Económico de los Desastres Naturales en la Infraestructura de Salud. Documento presentado en la conferencia. Internacional sobre Mitigación de Desastres en Instalaciones de Salud, 26-28 de Febrero, México D.F., 1996.

[21] Gaceta Oficial del Distrito Federal (In Spanish), Reglamento de Construcciones para el Distrito Federal, Report, Enero. 2004 Online http://www.crid.or.cr/digitalizacion/pdf/spa/doc7292/doc7292.htm. 